\section{COVID-19 Affects JNCCN}

A s I write this, my husband and I are in our 16th week of "sheltering in place," venturing out only for essential errands and necessities, wearing face coverings and clutching disinfectant wipes. Actually, it has not been that bad for us; we are fortunate to have space and lots of chores to occupy us. For some, it has been hard and frustrating on many levels. So, as America began to open up in early July, people became careless, perhaps thinking it was safe to resume normal activities. As a result, Texas hospitals at this very moment are scrambling for beds and ventilators, and other states are facing similar crises. This will be a long road to recovery.

Surprisingly, COVID-19 has affected JNCCN too. The first thing we noticed was a flood of submission inquiries about COVID-19-related articles. Physicians around the world clearly wanted to share experiences to help others. I'm proud that JNCCN was one of the first publications to discuss the effect of this pandemic on patients with cancer. The Seattle Cancer Care Alliance was one of the first epicenters of COVID-19 in America, and their experience has helped other centers across the country prepare and plan. Subsequently, NCCN's Best Practices Committee provided an important guide to ensure provider and patient safety in the setting of cancer care. In this issue, you will find a commentary that provides guidance on managing clinical trials in the midst of disruption caused by a pandemic.

Another thing we noticed was a surge of submissions in general. This is so impressive that I am including a graph comparing the number of submissions in the first half of 2019 versus the same period this year (Figure 1). We had a whopping 2.25-fold increase! Now, it could be just that JNCCN has achieved such a reputation that everyone wants to see their work in the journal, but I have a feeling that busy academics-who weren't traveling and who were perhaps seeing fewer patients-had extra time. What better time to crank out those manuscripts you've been wanting to get off your desk?

Finally, as we feverishly sorted through submissions, we learned of another change. JNCCN's impact factor jumped from 7.570 to 9.316, pushing the journal even higher in the ranks of oncology journals and into the top quartile of all medical journals. But COVID-19 cannot be credited for that; it can only be attributed to JNCCN's success in attracting better and more impactful manuscripts. Good for us!

So, in spite of COVID-19 and all the bad downstream consequences, JNCCN enjoyed some positive news. And goodness knows, we can all use positive news!

If you'd like to submit to JNCCN, go to www.editorialmanager.com/JNCCN.

Articles Submitted January-June, 2020 vs 2019

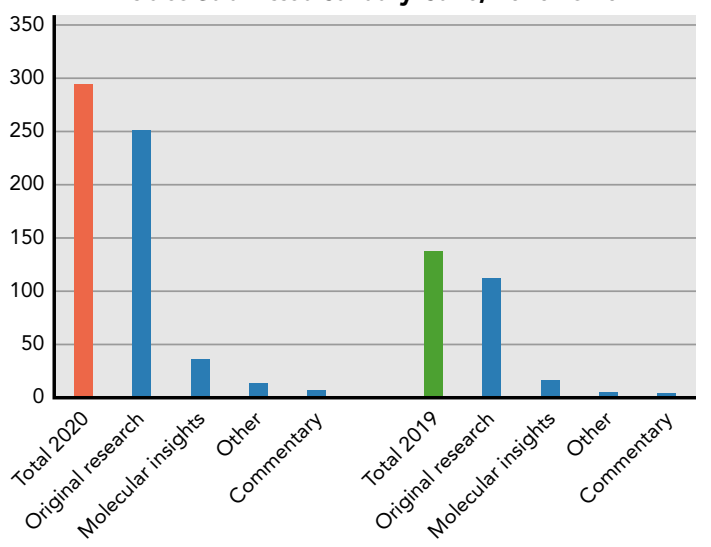

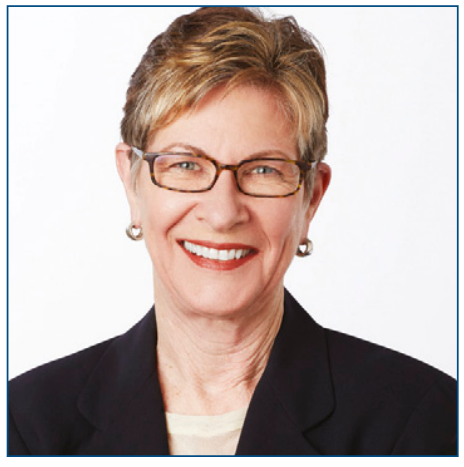

MARGARET TEMPERO, MD

Margaret Tempero, MD, is a Professor of Medicine and Director of the UCSF Pancreas Center and editor-in-chief of JNCCN. Her research career has focused on pancreatic ductal adenocarcinoma, especially in the area of investigational therapeutics. Dr. Tempero has served on the ASCO Board of Directors and as ASCO President. She currently serves on the ASCO Conquer Cancer Foundation Board. She codirected the AACR/ASCO Methods in Clinical Cancer Research and taught this course and similar courses in Europe and Australia. She was founding Chair of the $\mathrm{NCl}$ Clinical Oncology Study Section and served as a member and Chair of the $\mathrm{NCl}$ Board of Scientific Counselors Subcommittee A. She is a member of the Scientific Steering Committee and Chair of the Clinical and Translational Study Section for the Cancer Prevention \& Research Institute of Texas. She is or has been on the Scientific Advisory Boards of the Lustgarten Foundation, the Pancreatic Cancer Action Network, the V Foundation, The Alberta Canada Cancer Board, and the EORTC. She served as a member of the Oncology Drug Advisory Committee for the FDA. She has served as Deputy Director and Interim Director for the UNMC Eppley Cancer Center. She is Chief Emeritus of the Division of Medical Oncology at UCSF. She served as the founding Deputy Director and was later Director of Research Programs at the UCSF Helen Diller Family Comprehensive Cancer Center.

doi: $10.6004 /$ jnccn.2020.0038

The ideas and viewpoints expressed in this editorial are those of the author and do not necessarily represent any policy, position, or program of NCCN. 